\section{Regards sur l'économie allemande}

Bulletin économique du CIRAC

$85 \mid 2008$

Varia

\title{
Industries de réseaux
}

GERSDORF Hubertus, Entgeltregulierung im Eisenbahnsektor / KNIEPS

Günter, Netzökonomie. Grundlagen - Strategien - Wettbewerbspolitik / Telekommunikations- und Multimediarecht

\section{(2) OpenEdition}

12 Journals

Édition électronique

URL : https://journals.openedition.org/rea/410

DOI : $10.4000 /$ rea. 410

ISBN : 978-2-8218-0866-9

ISSN : 1965-0787

Éditeur

CIRAC

Édition imprimée

Date de publication : 1 mars 2008

ISSN : 1156-8992

Référence électronique

"Industries de réseaux", Regards sur l'économie allemande [En ligne], 85 | 2008, document 5, mis en

ligne le 22 avril 2008, consulté le 08 décembre 2022. URL : http://journals.openedition.org/rea/410 ; DOI : https://doi.org/10.4000/rea.410

Ce document a été généré automatiquement le 29 septembre 2020.

Tous droits réservés 


\section{Industries de réseaux}

GERSDORF Hubertus, Entgeltregulierung im Eisenbahnsektor / KNIEPS

Günter, Netzökonomie. Grundlagen - Strategien - Wettbewerbspolitik /

Telekommunikations- und Multimediarecht

\section{RÉFÉRENCE}

GERSDORF Hubertus, Entgeltregulierung im Eisenbahnsektor, Duncker \& Humblot, Berlin, 2007, $72 \mathrm{p}$.

KNIEPS Günter, Netzökonomie. Grundlagen - Strategien - Wettbewerbspolitik,

Gabler, Wiesbaden, 2007, 210 p.

Telekommunikations- und Multimediarecht, Deutscher Taschenbuch Verlag,

Munich, 7e éd., 2007, 586 p.

1 L'économie des industries de réseaux obéit à des lois particulières. Pour n'en donner qu'un exemple : les infrastructures et les services constituent deux marchés distincts, impliquant des stratégies de fixation des prix différentes de celles des autres activités industrielles. Cette situation pose un défi à la régulation de ces anciens services public en voie de libéralisation (télécommunications, chemins de fer, énergie, services postaux), soulevant notamment cette question: quels sont les segments ou marchés pertinents à considérer sous l'angle du droit de la concurrence ? Un manuel destiné aux étudiants et enseignants en sciences économiques dresse une vue d'ensemble de ces spécificités (KNIEPS). On la complètera utilement à la lecture des deux autres ouvrages : le recueil actualisé des lois s'appliquant en Allemagne au secteur des télécommunications et services multimédias - publié chez l'éditeur Beck au format de poche!-, ainsi qu'une analyse de la problématique des coûts et prix dans le secteur ferroviaire (GERSDORF). (ib) 